\title{
Status Report on NEAMS PROTEUS/ORIGEN Integration
}

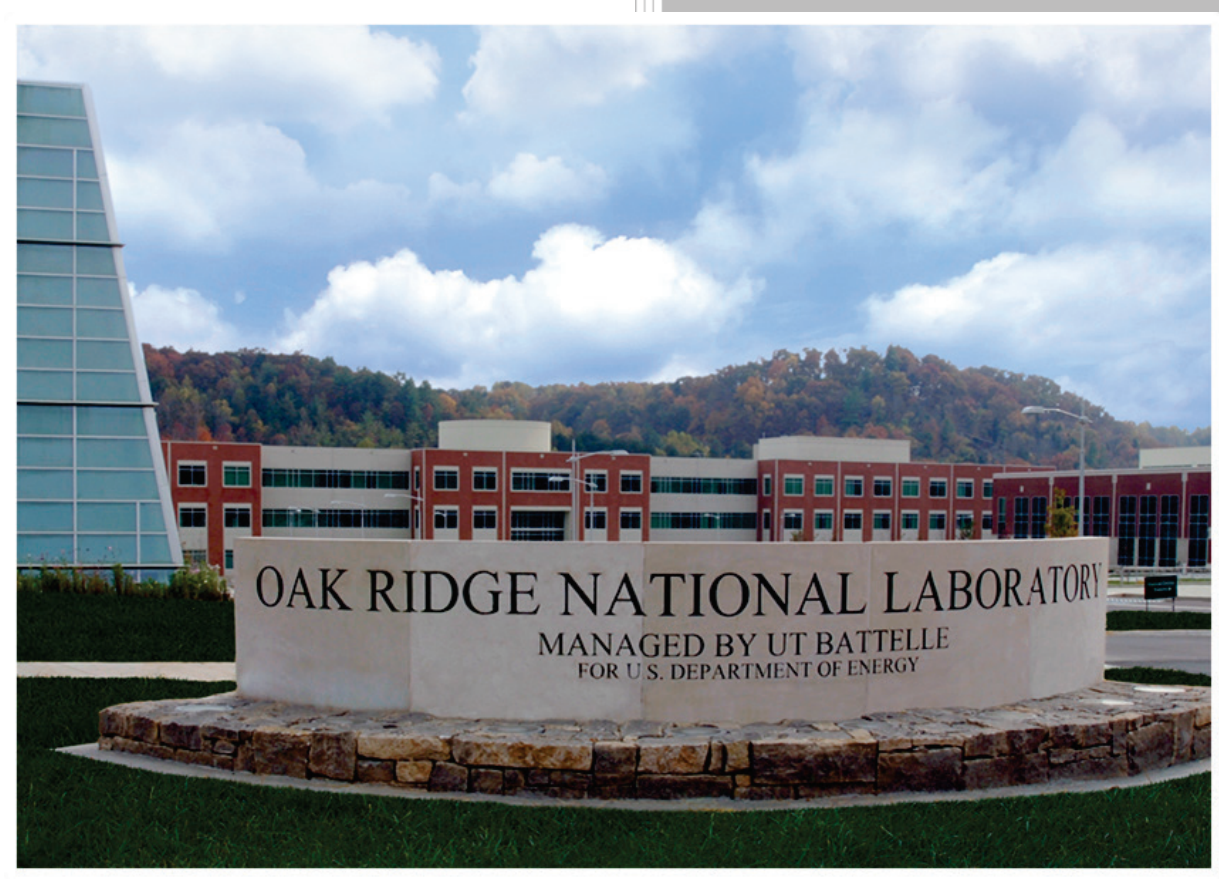

W. A. Wieselquist

Approved for public release. Distribution is unlimited. 


\title{
DOCUMENT AVAILABILITY
}

Reports produced after January 1, 1996, are generally available free via US Department of Energy (DOE) SciTech Connect.

\section{Website http://www.osti.gov/scitech/}

Reports produced before January 1, 1996, may be purchased by members of the public from the following source:

\author{
National Technical Information Service \\ 5285 Port Royal Road \\ Springfield, VA 22161 \\ Telephone 703-605-6000 (1-800-553-6847) \\ TDD 703-487-4639 \\ Fax 703-605-6900 \\ E-mail info@ntis.gov \\ Website http://www.ntis.gov/help/ordermethods.aspx
}

Reports are available to DOE employees, DOE contractors, Energy Technology Data Exchange representatives, and International Nuclear Information System representatives from the following source:

Office of Scientific and Technical Information

PO Box 62

Oak Ridge, TN 37831

Telephone 865-576-8401

Fax 865-576-5728

E-mail reports@osti.gov

Website http://www.osti.gov/contact.html

This report was prepared as an account of work sponsored by an agency of the United States Government. Neither the United States Government nor any agency thereof, nor any of their employees, makes any warranty, express or implied, or assumes any legal liability or responsibility for the accuracy, completeness, or usefulness of any information, apparatus, product, or process disclosed, or represents that its use would not infringe privately owned rights. Reference herein to any specific commercial product, process, or service by trade name, trademark, manufacturer, or otherwise, does not necessarily constitute or imply its endorsement, recommendation, or favoring by the United States Government or any agency thereof. The views and opinions of authors expressed herein do not necessarily state or reflect those of the United States Government or any agency thereof. 


\title{
Reactor and Nuclear Systems Division
}

\section{Status Report on NEAMS PROTEUS/ORIGEN Integration}

\author{
W. A. Wieselquist
}

Date Published: February 18, 2016

Prepared by

OAK RIDGE NATIONAL LABORATORY

Oak Ridge, TN 37831-6283

managed by

UT-BATTELLE, LLC

for the

US DEPARTMENT OF ENERGY

under contract DE-AC05-00OR22725 



\section{CONTENTS}

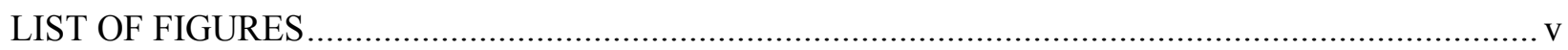

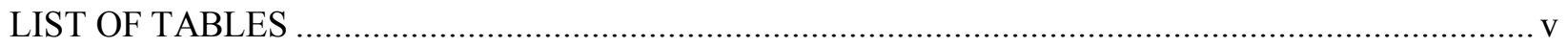

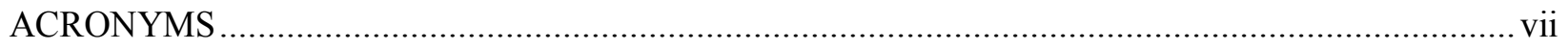

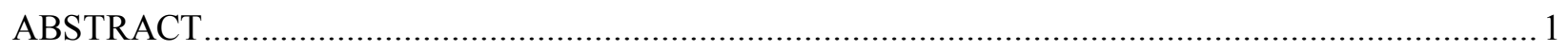

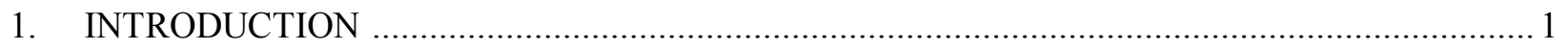

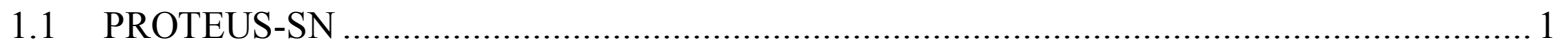

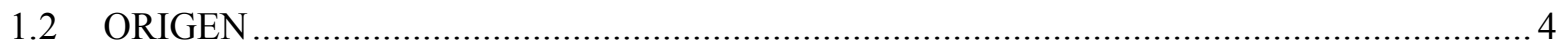

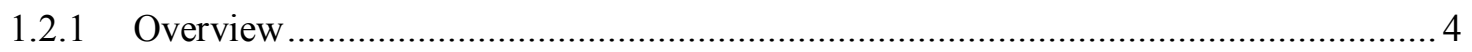

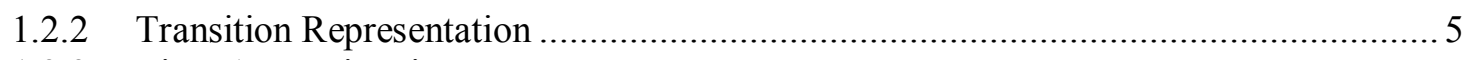

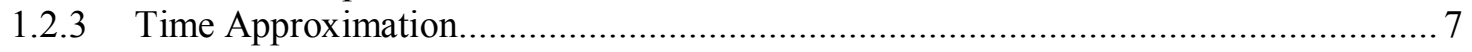

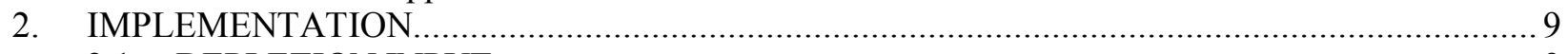

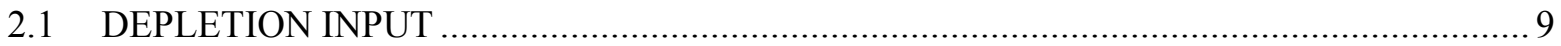

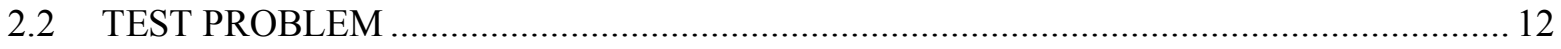

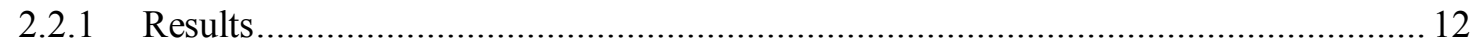

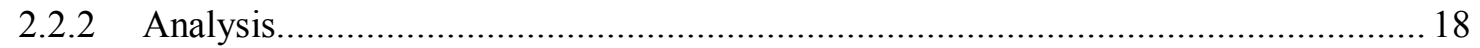

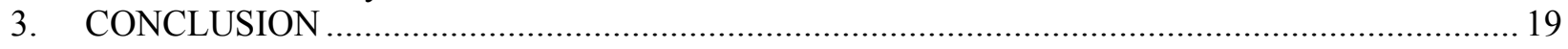

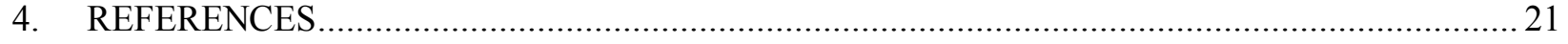





\section{LIST OF FIGURES}

Figure 1. SHARP Framework for Reactor Physics.

Figure 2. Visualization of 3D geometry and mesh used to analyze the Advanced Test Reactor with PROTEUS-SN.

Figure 3. Advanced Test Reactor fast (left) and thermal (right) flux calculated by PROTEUS-SN........... 3

Figure 4. Advanced Test Reactor fast (left) and thermal (right) flux calculated by PROTEUS-SN for a $2 \mathrm{D}$ calculation

Figure 5. Visualization of the transition matrix for fission products............................................... 5

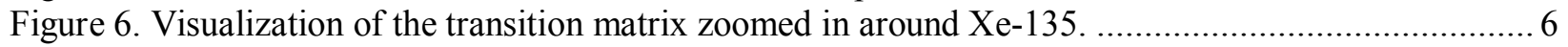

Figure 7. Example of PROTEUS-SN main input (file "unic.inp"). .................................................. 10

Figure 8. Example of PROTEUS-SN depletion input (file "depletion.inp"). ......................................... 10

Figure 9. Example of PROTEUS-SN assignment input (file "initial.assignment"). ............................... 11

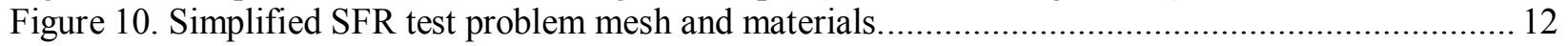

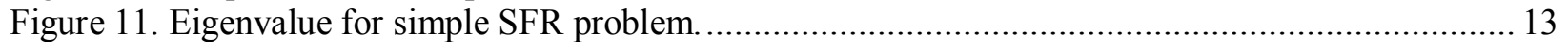

Figure 12. Total scalar flux in each material for simple SFR problem............................................ 14

Figure 13. Power distribution in SFR core at various times. ........................................................ 15

Figure 14. Absorption rate distribution in SFR core at various times. ........................................... 16

Figure 15. Fast flux, intermediate, and thermal distribution in SFR core at various times...................... 17

\section{LIST OF TABLES}

Table 1. Auxiliary input controls for "depletion.inp". 11

Table 2. Problem materials 



\section{ACRONYMS}

1D, 2D, 3D

API

ATR

CFD

CRAM

HDF5

MOC

NEAMS

ODE

ORIGEN

SAM

SFR

SGAPI one-, two-, three-dimensional

application programming interface

Advanced Test Reactor

computational fluid dynamics

Chebyshev Rational Approximation Method

Hierarchical Data Format, Version 5

method of characteristics

Nuclear Energy Advanced Modeling and Simulation

ordinary differential equation

Oak Ridge Isotope Generation and Depletion Code

Sodium-cooled fast reactor Analysis Module

sodium-cooled fast reactor

Sub-Group API 



\begin{abstract}
The US Department of Energy's Nuclear Energy Advanced Modeling and Simulation (NEAMS) Program has contributed significantly to the development of the PROTEUS neutron transport code at Argonne National Laboratory and to the Oak Ridge Isotope Generation and Depletion Code (ORIGEN) depletion/decay code at Oak Ridge National Laboratory. PROTEUS's key capability is the efficient and scalable (up to hundreds of thousands of cores) neutron transport solver on general, unstructured, threedimensional finite-element-type meshes. The scalability and mesh generality enable the transfer of neutron and power distributions to other codes in the NEAMS toolkit for advanced multiphysics analysis. Recently, ORIGEN has received considerable modernization to provide the high-performance depletion/decay capability within the NEAMS toolkit. This work presents a description of the initial integration of ORIGEN in PROTEUS, mainly performed during FY 2015, with minor updates in FY 2016.
\end{abstract}

\title{
1. INTRODUCTION
}

The US Department of Energy's Nuclear Energy Advanced Modeling and Simulation (NEAMS) Program has contributed significantly to the development of the PROTEUS neutron transport code at Argonne National Laboratory and to the Oak Ridge Isotope Generation and Depletion Code (ORIGEN) at Oak Ridge National Laboratory. This work presents a description of the initial integration of ORIGEN in PROTEUS.

The following sections serve to familiarize the reader with the PROTEUS-SN solver and ORIGEN and to introduce the basic variables and input where appropriate.

\subsection{PROTEUS-SN}

PROTEUS is actually a suite of neutron transport algorithms [2] able to solve neutron and gamma transport problems on large, unstructured finite element meshes. It includes the following solvers:

- $\mathrm{S}_{\mathrm{N}}$ solver,

- $\quad \mathrm{P}_{\mathrm{N}}$ solver,

- general three-dimensional (3D) method of characteristics (MOC), and

- an experimental 2D/1D method based on MOC in 2D and $\mathrm{P}_{\mathrm{N}}$ in a $1 \mathrm{D}$ axial geometry with special constraints of an "extruded" geometry/mesh, such that the domain is divided into axial "slices."

Like most of the current applications in NEAMS, this work utilizes the $\mathrm{S}_{\mathrm{N}}$ solver, which is referred to as PROTEUS-SN. It is the most mature and scalable solver and thus is the workhorse for full system simulations (SHARP), which coupled PROTEUS to Nek 5000 (computational fluid dynamics) and Diablo (structural mechanics) through MOAB, as shown in Figure 1. 


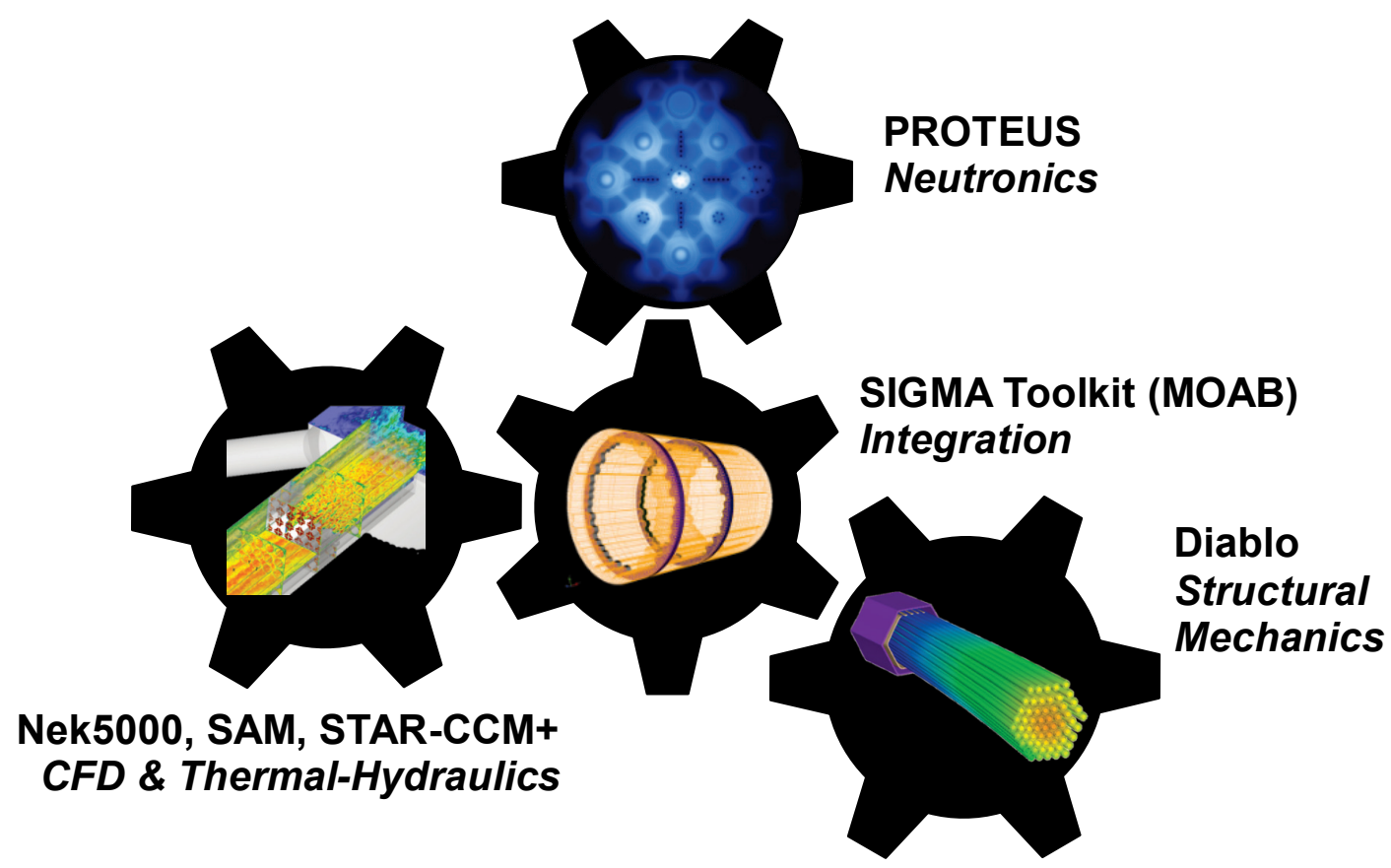

Figure 1. SHARP Framework for Reactor Physics.

A useful property of PROTEUS is the ability to produce Hierarchical Data Format Version 5 (HDF5) files containing the mesh and neutron and power distribution that can be natively imported in VisIt, a tool for high-performance visualization [4] using the "UNIC" plugin (the former name of PROTEUS).

Figure 2 shows an example of a mesh generated for the Advanced Test Reactor (ATR), with scalar flux plots shown in Figure 3 (3D) and Figure 4 (2D overhead view).
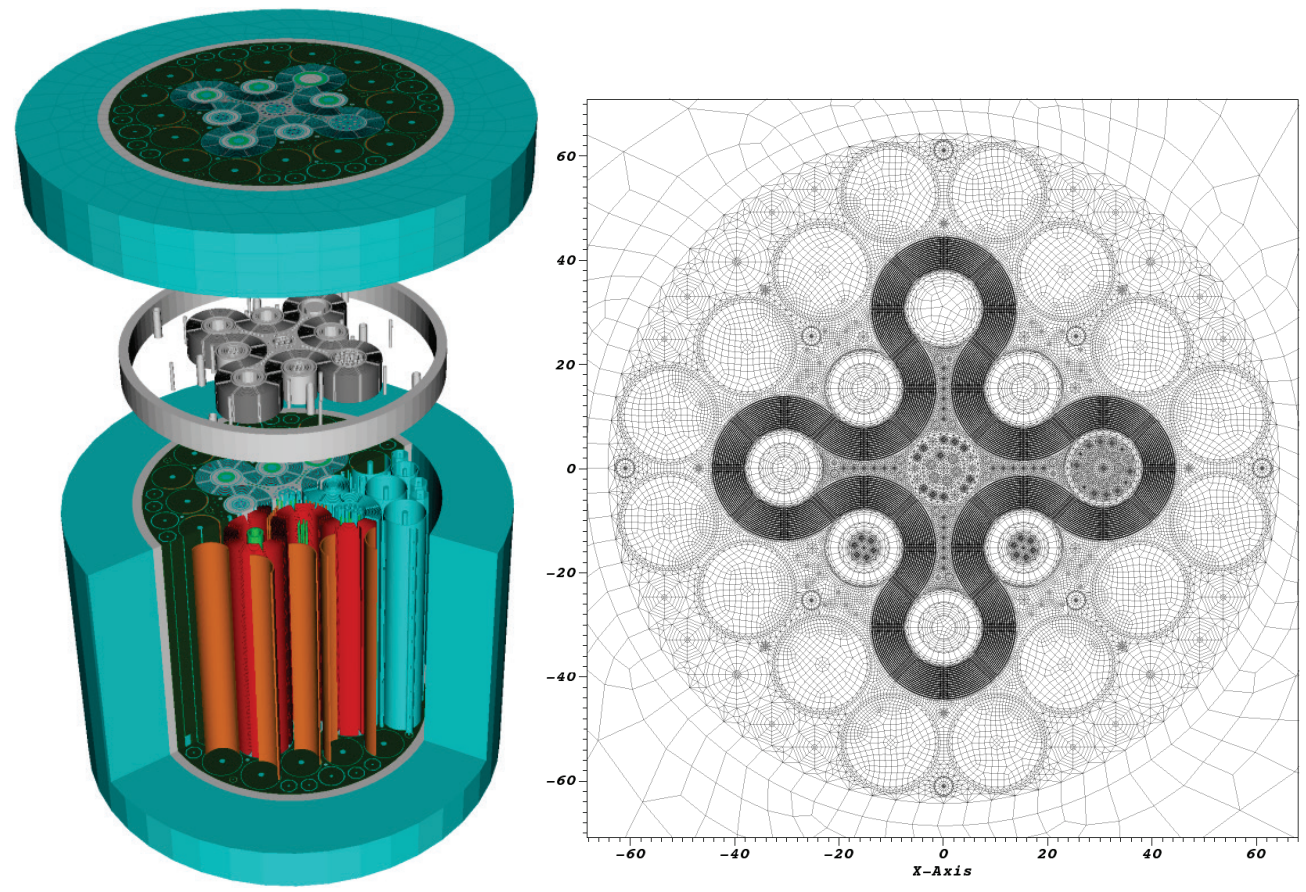

Figure 2. Visualization of 3D geometry and mesh used to analyze the Advanced Test Reactor with PROTEUS-SN. 


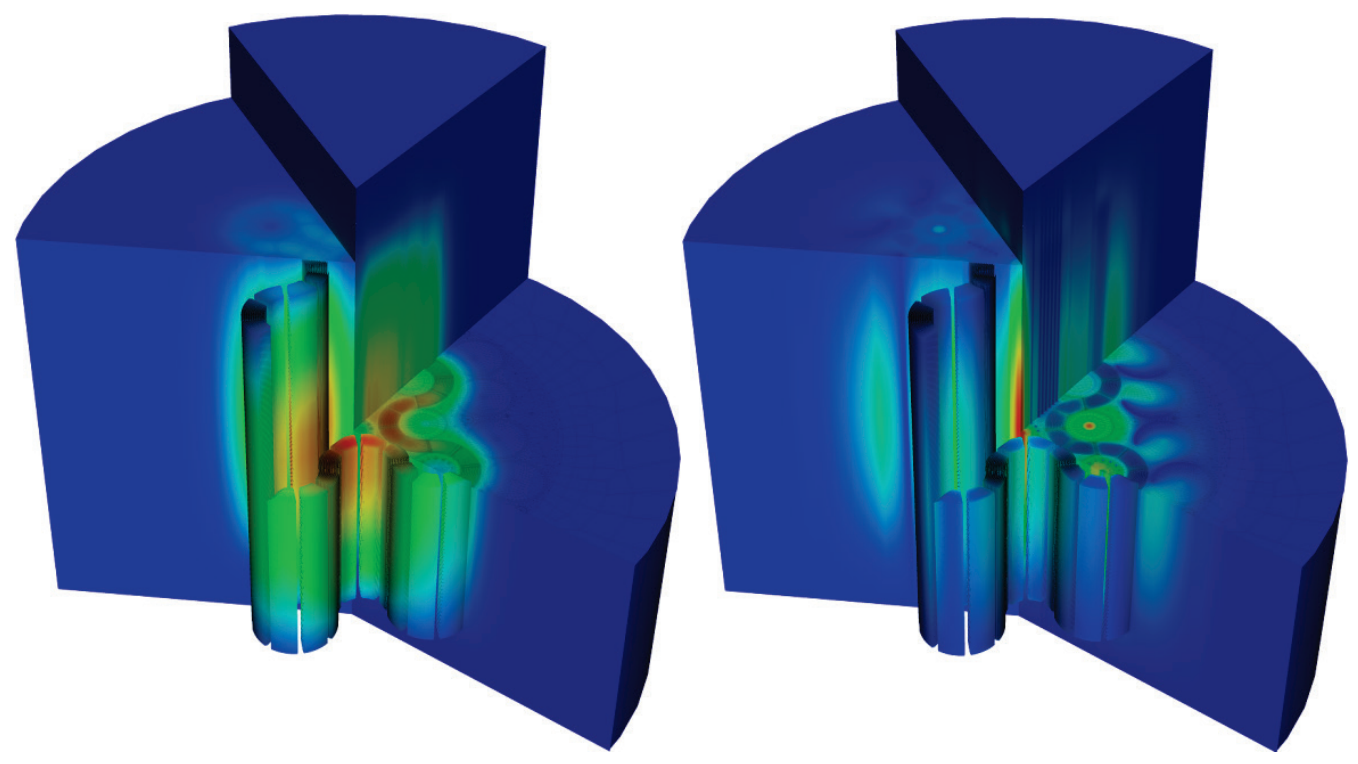

Figure 3. Advanced Test Reactor fast (left) and thermal (right) flux calculated by PROTEUS-SN.
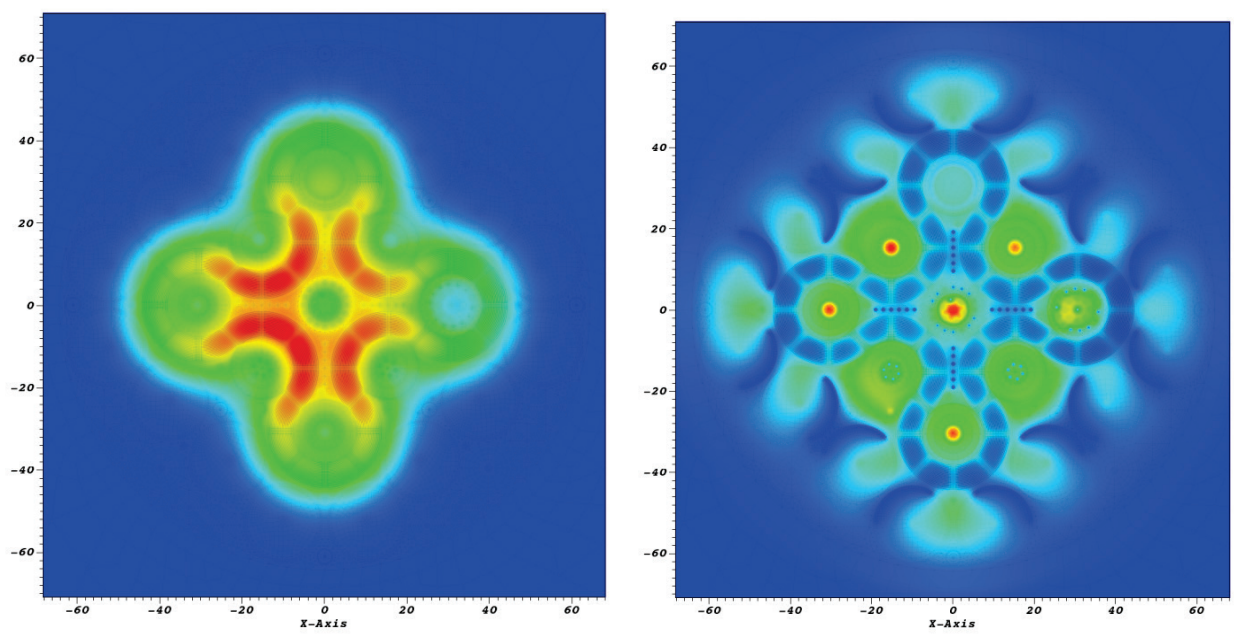

Figure 4. Advanced Test Reactor fast (left) and thermal (right) flux calculated by PROTEUS-SN for a 2D calculation.

Additional capabilities of PROTEUS-SN include the capability to solve both fixed-source and eigenvalue problems in forward and adjoint modes. The principal solution of the PROTEUS-SN code is the multigroup angular flux at all finite element vertices. For the purposes of coupling to depletion, a larger region called a "block" or "material" is defined, which is a collection of finite elements that have the same cross-section data. The material-average scalar flux is defined as

$$
\Phi_{m}^{g}=\frac{1}{\sum_{e \in m} V_{e}} \sum_{e \in m} V_{e} \sum_{k \in e} f_{k} \sum_{n} w_{n} \Psi_{k n}^{g},
$$


where the weights $w_{n}$ are the angular cubature weights for direction index $n$ and angular flux $\Psi_{k n}^{g}$, at finite element vertex $k$ with integration weight $f_{k}$, for a finite element $e$, with volume $V_{e}$, for all elements in material/block $m$.

The PROTEUS code has three ways to determine multigroup cross sections [3].

1. a static set of cross sections can be read from a standard ISOTXS binary library file,

2. a static set of cross sections can be read from a special ANLXS text file and converted to ISOTXS, or

3. the Sub-Group API (SGAPI) in SHARP can be used for on-the-fly cross-section calculations.

\subsection{ORIGEN}

ORIGEN has been used to model nuclide transmutation for over 40 years. It has the capability to generate source terms for accident analyses, characterize used fuel (including activity, decay heat, radiation emission rates, and radiotoxicity), activate structural materials, and perform fuel cycle analysis studies $[5,6]$. This wide range of applications is possible because the guiding principle has been to explicitly simulate all decay and neutron reaction pathways using the best available data and to rigorously validate the result vs experiment. ORIGEN has been subject to hundreds of validation cases [7] using measured data from the destructive isotopic assay of spent fuel, decay heat of spent fuel, gamma spectra resulting from burst fission, and neutron spectra resulting from spontaneous fission and $(\alpha, n)$ reactions.

An active modernization has taken place over the last few years [8], and the ORIGEN depletion/decay module has received extensive improvement, including an application programming interface (API) for both $\mathrm{C}++$ and Fortran with modern object-oriented design and various solver enhancements. This paper highlights the API capabilities that are currently available for embedding ORIGEN depletion calculations in other codes [9].

\subsubsection{Overview}

The fundamental purpose of ORIGEN and the new API is to solve the following system of ordinary differential equations (ODEs) describing the depletion/decay phenomena:

$$
\frac{d \vec{n}_{m}}{d t}=\left(\boldsymbol{A}_{\phi m} \Phi_{m}+\boldsymbol{A}_{\lambda}\right) \vec{n}_{m}(t)+\vec{S}_{m}(t)
$$

where

- $m$ is a material index,

- $\vec{n}_{m}$ is the nuclide number density vector for material $m$ (atoms/barn-cm),

- $\boldsymbol{A}_{\phi m}$ is the transition matrix for the reaction transitions (barns or $\mathrm{cm}^{2}$ ),

- $\Phi_{m}$ is the scalar flux magnitude $\left(1 / \mathrm{cm}^{2} s\right)$,

- $\boldsymbol{A}_{\lambda}$ is the transition matrix for decay transitions $(1 / s)$, and

- $\vec{S}_{m}$ is an external source.

The ORIGEN API solves the above system of ODEs for large systems (thousands of nuclides/tens of thousands of transitions). In traditional coupling to neutron transport codes, a quasi-static approximation is used to approximate the evolution of the system with time, where

- the steady-state, transport eigen-problem or fixed-source problem is solved at time points, (with appropriate problem-dependent self-shielding of cross sections) and 
- the depletion equations of Eq. (2) are solved over each time step.

In typical coupled transport/depletion simulations, the a fixed amount of initial material is present in each depletable zone and the external source $\vec{S}_{m}(t)$ (i.e., feed of material into the volume) is zero.

\subsubsection{Transition Representation}

A visualization of the full transition matrix, $\boldsymbol{A}=\boldsymbol{A}_{\phi}+\boldsymbol{A}_{\lambda}$, for $\sim 1200$ fission products is shown in Figure 5; a zoomed-in view of Xe-135 is shown in Figure 6. Solid colored lines are used for reaction transitions, and dashed green lines are used for decay transitions.

The decay portion, $\boldsymbol{A}_{\boldsymbol{\lambda}}$, of the transition matrix is given by row as

$$
a_{\lambda, i i^{\prime}} \stackrel{\text { def }}{=} \begin{cases}\gamma_{d, i \leftarrow i^{\prime}} \lambda_{d, i^{\prime}} & \text { for } i \neq i^{\prime} \\ -\sum_{d} \lambda_{d, i} & \text { for } i=i^{\prime}\end{cases}
$$

where $d$ indicates a decay mode, the top term (off-diagonal) represents gains of nuclide $i$ due to decay mode $d$, and the bottom term (diagonal) represents the loss of nuclide $i$ due to all decay modes. The decay portion is independent of material $m$.

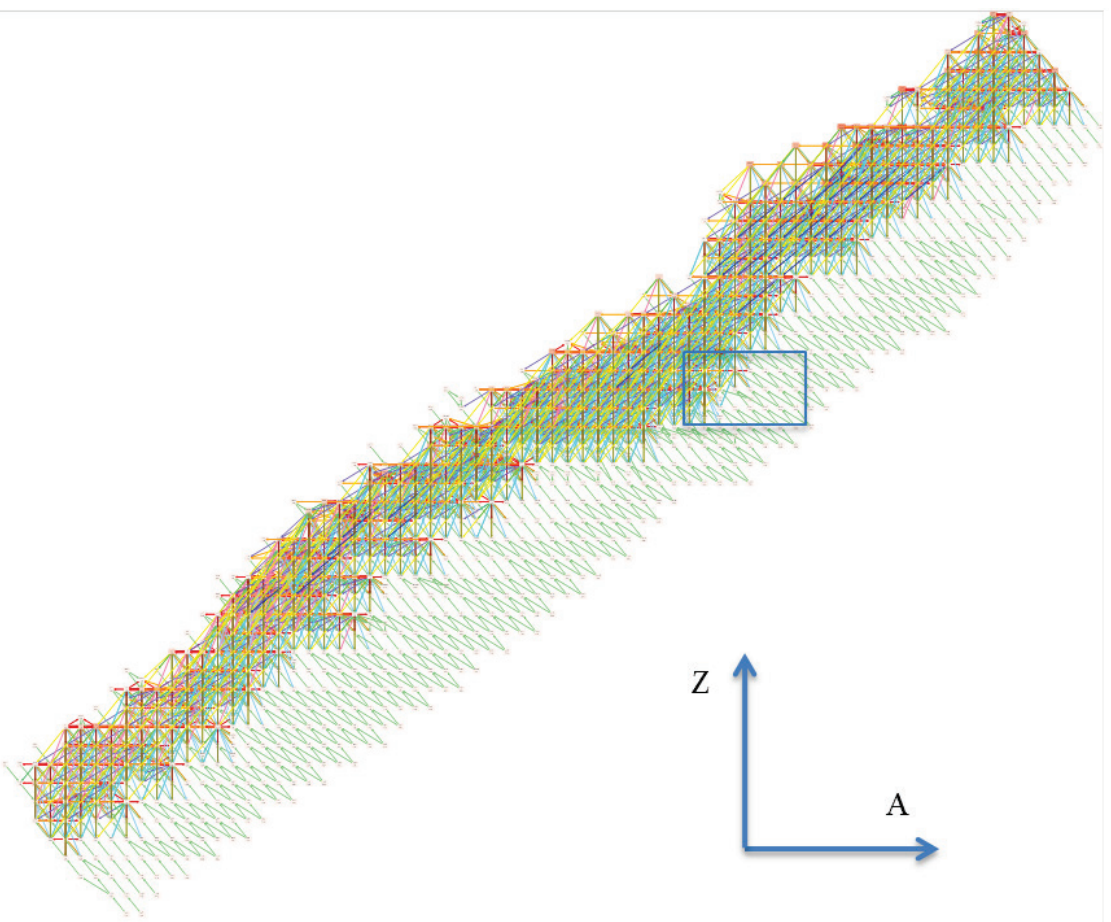

Figure 5. Visualization of the transition matrix for fission products. 


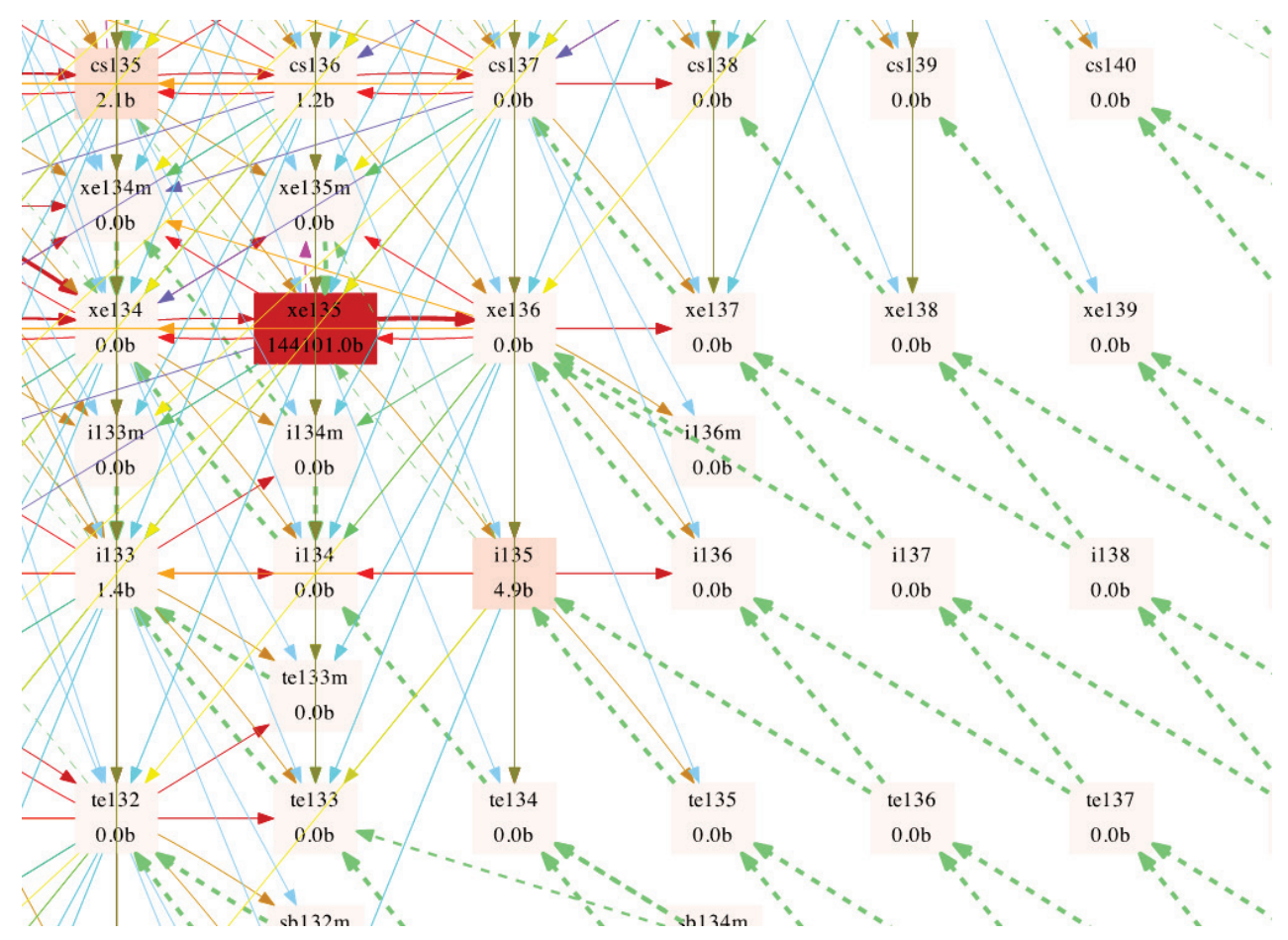

Figure 6. Visualization of the transition matrix zoomed in around Xe-135.

The reaction part is treated in essentially the same way, with the off-diagonal entries in the matrix $\boldsymbol{A}_{\phi m}$ defining the creation of nuclide $i$ from reaction transitions of all other nuclides $i^{\prime}$. The structure of each row of $\boldsymbol{A}_{\phi m}$ is

$$
a_{\phi m, i i^{\prime}} \stackrel{\text { def }}{=} \begin{cases}\gamma_{x m, i \leftarrow i^{\prime}} \sigma_{x m, i^{\prime}} & \text { for } i \neq i^{\prime} \\ -\sum_{x} \sigma_{x m, i} & \text { for } i=i^{\prime}\end{cases}
$$

where the top term (off-diagonal) represents gains of nuclide $i$ due to reaction type $x$ and the bottom term (diagonal) represents the loss of nuclide $i$ due to all reaction mechanisms. The gain term is convenient to represent in terms of "yield," $\gamma_{x m, i \leftarrow i}$ ', and reaction cross section, $\sigma_{x m, i}$ '.

The use of a "yield" $\gamma$ is convenient for modeling not only fission (where it is a necessity) but also for modeling isomeric branching and by-product production. For example, in an isomeric-branching model in which the $(n, \gamma)$ reaction cross section of U-234 is 1 barn and both U-235 $(99 \%)$ and U-235m (1\%) are produced, ORIGEN would have $\sigma_{(n, \gamma), U 4}=1 \mathrm{barn}, \gamma_{(n, \gamma), U 5 m \leftarrow U 4}=1 \%$, and $\gamma_{(n, \gamma), U 5 \leftarrow U 4}=99 \%$, indicating that $1 \%$ of the reactions go to the first metastable state of U-235 and $99 \%$ go directly to the ground state. Byproduct protons, deuterons, tritons, helions (He-3), and alphas emitted in reaction/decay transitions are tracked by ORIGEN explicitly with yield the multiplicity of the product; for example, an $(n, \alpha)$ reaction results in a gain term for the alpha by-product of $\gamma_{(n, \alpha), \alpha \leftarrow *}=1$, and an $(n, 2 \alpha)$ reaction results in $\gamma_{(n, 2 \alpha), \alpha \leftarrow *}=2$, with "*" indicating validity for any parent nuclide. In the case of fission and isomeric reaction transitions, the yield is dependent on the neutron spectrum. For by-products, the yield is a constant. ORIGEN contains an extensive multigroup reaction cross-section library based on JEFF/3.1-A with more than 12,000 cross sections for the following reactions: $(n, 2 n),(n, 3 n),(n, f),(n, n \alpha),(n, n 3 \alpha)$, 
$(n, 2 n \alpha),(n, 3 n \alpha),(n, n p),(n, n 2 \alpha),(n, 2 n 2 \alpha),(n, n d),(n, n t),\left(n, n^{3} H e\right),(n, n d 2 \alpha),(n, n t 2 \alpha),(n, 4 n),(n, g),(n, p)$, $(n, d),(n, t),\left(n,{ }^{3} H e\right),(n, \alpha),(n, 2 \alpha),(n, 3 \alpha),(n, 2 p),(n, p \alpha),(n, t 2 \alpha),(n, d 2 \alpha),(n, n)$. In typical activation problems, where self-shielding is not important, given a multigroup neutron flux spectrum, the JEFF library is sufficient to calculate the one-group cross sections and yields needed to perform transmutation calculations.

Given the groupwise neutron spectrum $\phi_{m}^{g}$, where $g$ is the multigroup energy index, the one-group cross sections used by ORIGEN are calculated with standard flux weighting:

$$
\sigma_{x m, i}=\frac{\sum_{g} \sigma_{x m, i}^{g} \phi_{m}^{g}}{\sum_{g} \phi_{m}^{g}}
$$

For isomeric reaction branching, energy-dependent yields are calculated as

$$
\gamma_{x m, i \leftarrow i \prime}=\frac{\sum_{g} \gamma_{x, i \leftarrow i}^{g} \sigma_{x, i}^{g} \phi_{m}^{g}}{\sigma_{x, i}},
$$

where the multigroup yield term, $\gamma_{x, i \leftarrow i}^{g}$, and weighting cross section, $\sigma_{x, i}^{g}$, are contained on the JEFF library and are independent of material. For fission yields, the average energy of fission is calculated and linear interpolation is performed on yields tabulated at one to three discrete energy points,

$$
\gamma_{f m, i \leftarrow i}=\operatorname{interp}\left(E_{f m, i^{\prime}}, \gamma_{f, i \leftarrow i}\left(E_{1}\right), \gamma_{f, i \leftarrow i}\left(E_{2}\right), \ldots\right)
$$

where the average energy of fission in actinide $i^{\prime}$, which creates fission products $i$, is given as

$$
E_{f m, i^{\prime}}=\frac{\sum_{g} \bar{E}_{g} \sigma_{f m, i}^{g} \phi_{m}^{g}}{\sum_{g} \sigma_{f m, i}^{g} \phi_{m}^{g}},
$$

where $\bar{E}_{g}$ is some average energy for group $g$ that depends only on the group structure.

\subsubsection{Time Approximation}

To resolve the no-linear dependence of the depletion/decay model in Eq. (2) on the evolution of the transport flux in time, the reaction transition matrix and flux magnitude are fixed at some known "average" value, $\overline{\boldsymbol{A}}_{\phi m, j}$ and $\bar{\Phi}_{m, j}$,

$$
\begin{gathered}
\frac{d \vec{n}_{m}}{d t}=\left(\overline{\boldsymbol{A}}_{\phi m, j} \bar{\Phi}_{m, j}+\boldsymbol{A}_{\lambda}\right) \vec{n}_{m}(t), \\
\text { over step } t_{j} \leq t \leq t_{j+1}, \\
\text { with initial condition } \vec{n}_{m}\left(t_{j}\right)=\vec{n}_{m, j}
\end{gathered}
$$

where

- $\bar{\Phi}_{m, j}$ is the step-average material flux $\left(1 / \mathrm{cm}^{2} s\right)$ and 
- $\overline{\boldsymbol{A}}_{\phi m, j}$ is the step-average reaction transition matrix (barns).

The representation in Eq. (9) assumes that the flux magnitude, $\bar{\Phi}_{m, j}=\sum_{g} \Phi_{m, j}^{g}$, will be available as a result of the transport calculation, which produces multigroup fluxes $\Phi_{m, j}^{g}=\Phi_{m}^{g}\left(t_{j}\right)$ at each transport solution time. The simple "predictor" (or explicit) approximation used in the current PROTEUS/ORIGEN coupling assumes that $\bar{\Phi}_{m, j}=\Phi_{m, j}$ and $\overline{\boldsymbol{A}}_{\phi m, j}=\boldsymbol{A}_{\phi m, j}$ (i.e., the average is approximated as the standard beginning-of-step value). 


\section{IMPLEMENTATION}

The current implementation relies on the ISOTXS multigroup cross-section library format for PROTEUSSN's cross-section data. This leads to the following important limitations in the current ORIGEN coupling.

- The user must provide a mapping of (arbitrary) ISOTXS nuclide labels to standard (ORIGEN) nuclide identifiers (IDs). This requires knowledge of the labels contained on the binary ISOTXS library and the nuclides to which they correspond. In many cases, this is as simple as mapping "U235_H" on the ISOTXS library to ORIGEN's "U235," but because the ISOTXS label is truly arbitrary, there can be labels such as "P9" or "LP," and an automatic conversion cannot be ensured to be correct (or detected when it fails).

- Elements such as "FE" and "NA" are not split into constituent nuclides because cross sections only exist for the element in the ISOTXS library and ORIGEN cannot currently update its nuclide-based reaction rates based on elemental reaction rates.

- A single, static system power value (total watts produced by the system) is allowed.

- Feedback of updated depletion isotopics to macroscopic transport cross sections is only performed for the nuclides that have been defined in the initial material. This is because the cross section-to-material mapping is performed when the input is read and data structures are distributed to all processes for the parallel computation. This is the only time such a send is allowed, and all data that are not needed are deleted.

Isotopics are currently not available on the HDF5 output file produced by PROTEUS.

\subsection{DEPLETION INPUT}

The PROTEUS input processor was modified to read depletion input similarly to the kinetics input, where the main input is read on "unic.inp" (see example in Figure 7), and additional input for the kinetics problem is read from "kinetics.inp." In the case of depletion, the additional input is called "depletion.inp" (an example is shown in Figure 8). A currently inconvenient feature of the input is the requirement for the user to define the mapping of cross-section nuclide names to actual names with multiple

"NUCLIDE_ALIAS" commands. An example of a material assignment file is shown in Figure 9. Table 1 shows the complete set of input controls allowed in the "depletion.inp" file, with a table style consistent with other input definitions in the PROTEUS-SN user manual [3]. 


\begin{tabular}{|c|c|}
\hline SN_TYPE & LEG-TCHEBY \\
\hline Thêta_Resolution & 2 \\
\hline Phi_Resolution & 2 \\
\hline SEGMENT_ANGLE & 2 \\
\hline DEBUG_PRINT_LEVEL & 0 \\
\hline DEBUG_PRINT_SETUP & 0 \\
\hline DEBUG_PRINT_FORMATION & 0 \\
\hline DEBUG_PRINT_OUTER & 0 \\
\hline THERMAL_POWER & 1.0e2 !Watts \\
\hline Scattering Order & 0 \\
\hline Tolerance_èigenvalue & $1.0 e-3$ \\
\hline Tolerance_Fission & $1.0 e-3$ \\
\hline Tolerance_Flux & $1.0 e-3$ \\
\hline Iterations_Fission & 400 \\
\hline Iterations_MaxUpScatter & 5 \\
\hline Iterations_MinUpScatter & 1 \\
\hline Iterations_scattering & 20 \\
\hline Iterations_SA_CG & 100 \\
\hline Iterations_PETSC & 1000 \\
\hline SOURCEFILE_MESH & bench.ascii \\
\hline SOURCEFILE_XS & bench_3g.anlxs \\
\hline SOURCEFILE_MATERIAL & initiāl.assignment \\
\hline
\end{tabular}

Figure 7. Example of PROTEUS-SN main input (file "unic.inp").

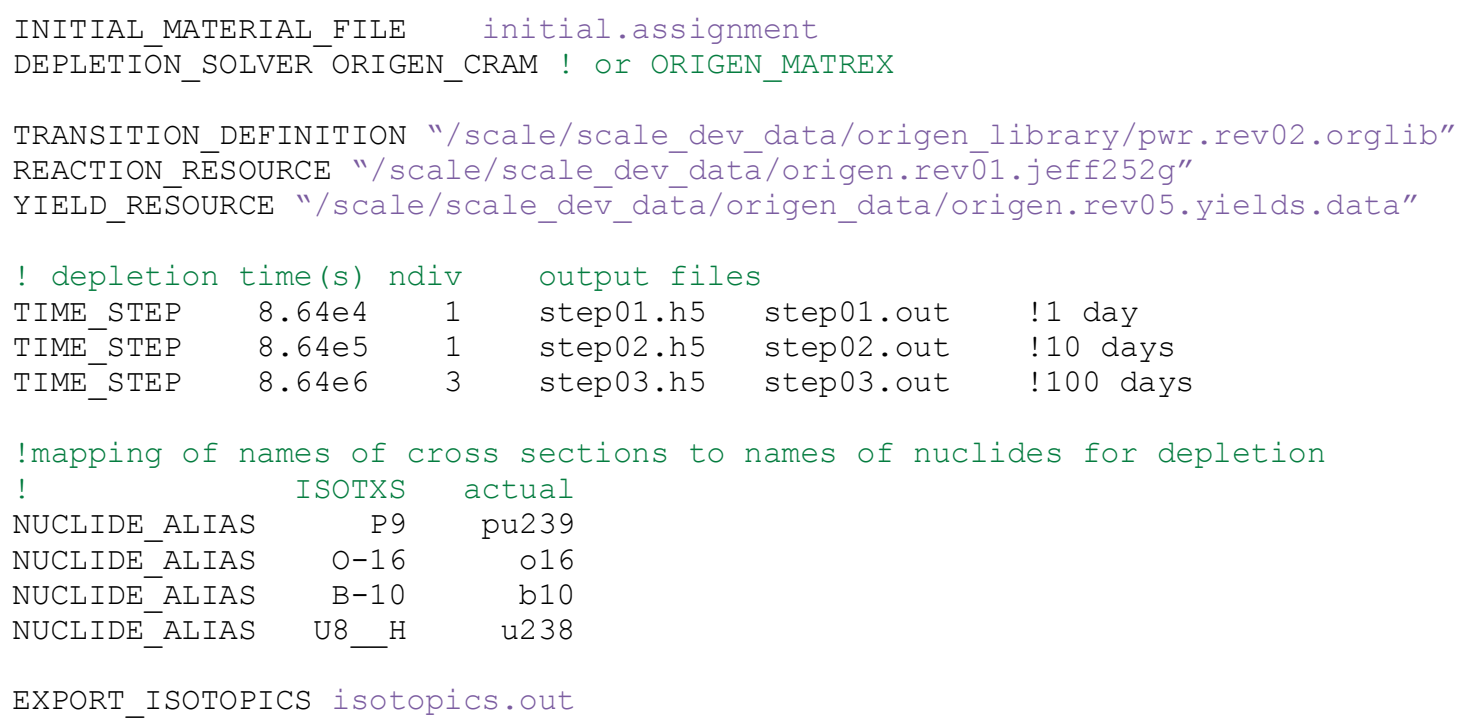

Figure 8. Example of PROTEUS-SN depletion input (file “depletion.inp”). 


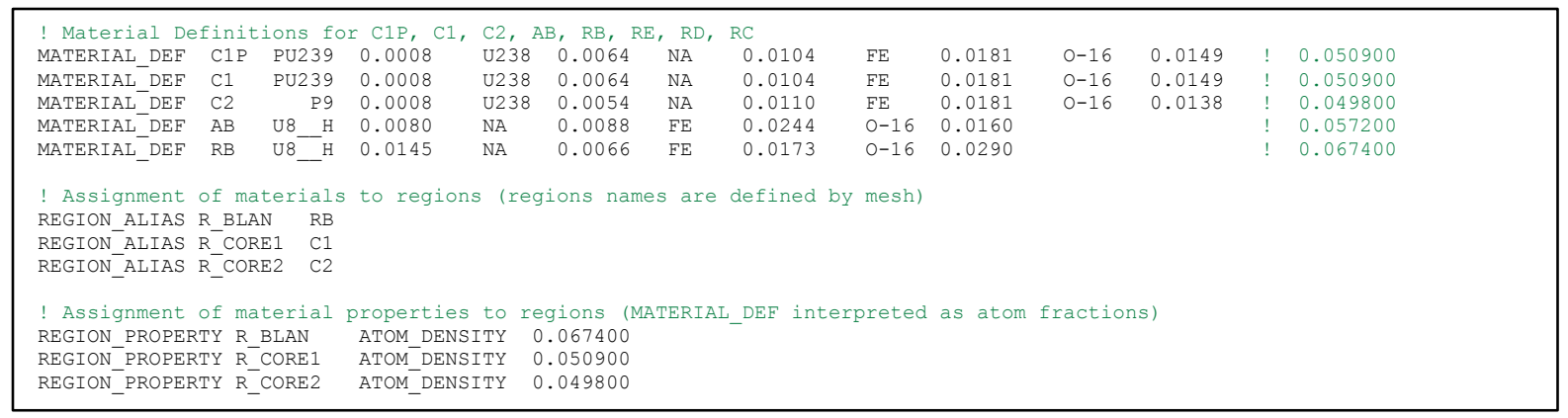

Figure 9. Example of PROTEUS-SN assignment input (file "initial.assignment").

Table 1. Auxiliary input controls for "depletion.inp"

\begin{tabular}{|c|c|c|c|}
\hline Keyword & Input data & Default value & Function \\
\hline INITIAL_MATERIAL_FILE & $\begin{array}{ll} & <\text { Filename }> \\
<128 \text { Character Name> }\end{array}$ & $\mathrm{NO}$ & $\begin{array}{l}\text { Loads the initial material } \\
\text { assignment file. }\end{array}$ \\
\hline DEPLETION_SOLVER & $\begin{array}{l}\text { ORIGEN_CRAM or } \\
\text { ORIGEN_MATREX }\end{array}$ & NO & $\begin{array}{l}\text { Whether to use Chebyshev } \\
\text { Rational Approximation Method } \\
\text { (CRAM) or legacy Matrix } \\
\text { Exponential Method (MATREX). }\end{array}$ \\
\hline TRANSITION_DEFINITION & $\begin{array}{ll} & <\text { Filename }> \\
<128 \text { Character Name }>\end{array}$ & depletion.td & $\begin{array}{l}\text { Definition of the nuclides and } \\
\text { transition to be included in the } \\
\text { depletion problem. Basically, the } \\
\text { sparsity pattern referred to in Eq. } \\
\text { (4). }\end{array}$ \\
\hline REACTION_RESOURCE & $\begin{array}{ll} & <\text { Filename }> \\
<128 \text { Character Name> }\end{array}$ & depletion.rr & $\begin{array}{l}\text { A multigroup cross-section } \\
\text { database for auxiliary reaction } \\
\text { transition calculations. Basically, } \\
\text { the data set referred to in Eq. (5). }\end{array}$ \\
\hline YIELD_RESOURCE & $\begin{array}{ll} & <\text { Filename }> \\
<128 \text { Character Name }>\end{array}$ & depletion.yr & $\begin{array}{l}\text { An energy-dependent fission yield } \\
\text { file. Basically, the data set referred } \\
\text { to in Eq. (6) and Eq. (7). }\end{array}$ \\
\hline TIME_STEP & $\begin{array}{l}<\text { Value }>\text { <Value> } \\
<\text { Filename.out }> \\
<\text { Filename.h5> }\end{array}$ & NO & $\begin{array}{l}\text { Create a time step. First }<\text { Value }> \\
\text { is length of the time step } \\
\text { (seconds), second the number of } \\
\text { substeps, and then (optionally) the } \\
\text { name of an HDF } 5 \text { dump file (.h5 } \\
\text { extension) or region-wise edit file } \\
\text { (.out extension). }\end{array}$ \\
\hline NUCLIDE_ALIAS & <ISOTXS> <actual> & NO & $\begin{array}{l}\text { Define a mapping from a nuclide } \\
\text { name in the cross-section library } \\
\text { to an actual nuclide, using the } \\
\text { form " }<\mathrm{e}><\mathrm{a}><\mathrm{m}>\text {," where }<\mathrm{e}>\text { is } \\
\text { the element symbol, }<\mathrm{a}>\text { is the } \\
\text { mass number, and }<\mathrm{m}>\text { is the } \\
\text { (optional) metastable indicator } \\
\text { (e.g., "u235" or "am } 242 \mathrm{~m} \text { "). }\end{array}$ \\
\hline EXPORT_ISOTOPICS & <128 Character Name> & isotopics.out & \\
\hline
\end{tabular}




\subsection{TEST PROBLEM}

The test problem is a simplified model of a sodium-cooled fast reactor (SFR) core, taken from the SHARP/PROTEUS repository (“modules/unic/src/verification/SN2ND_Kinetics/bench07") and modified to include depletion. The test uses a three-group ANLXS ${ }^{1}$ cross-section library with microscopic cross sections for U-238, Pu-239, Pu-240, Pu-241, O-16, and B-10 nuclides and group boundaries of $10 \mathrm{MeV}$, $800 \mathrm{keV}, 80 \mathrm{keV}$, and $0.4 \mathrm{eV}$. Thus only updated number densities for these isotopes feed back into the transport code, although there are isotopic results from ORIGEN available for the full set of $\sim 1200$ isotopes. Notably missing from the library are fission products, so the eigenvalue will be considerably higher in this test than it should be. The geometry and mesh of the northeast quadrant are shown in Figure 10 (i.e., the $x$-axis and $y$-axis are lines of symmetry.

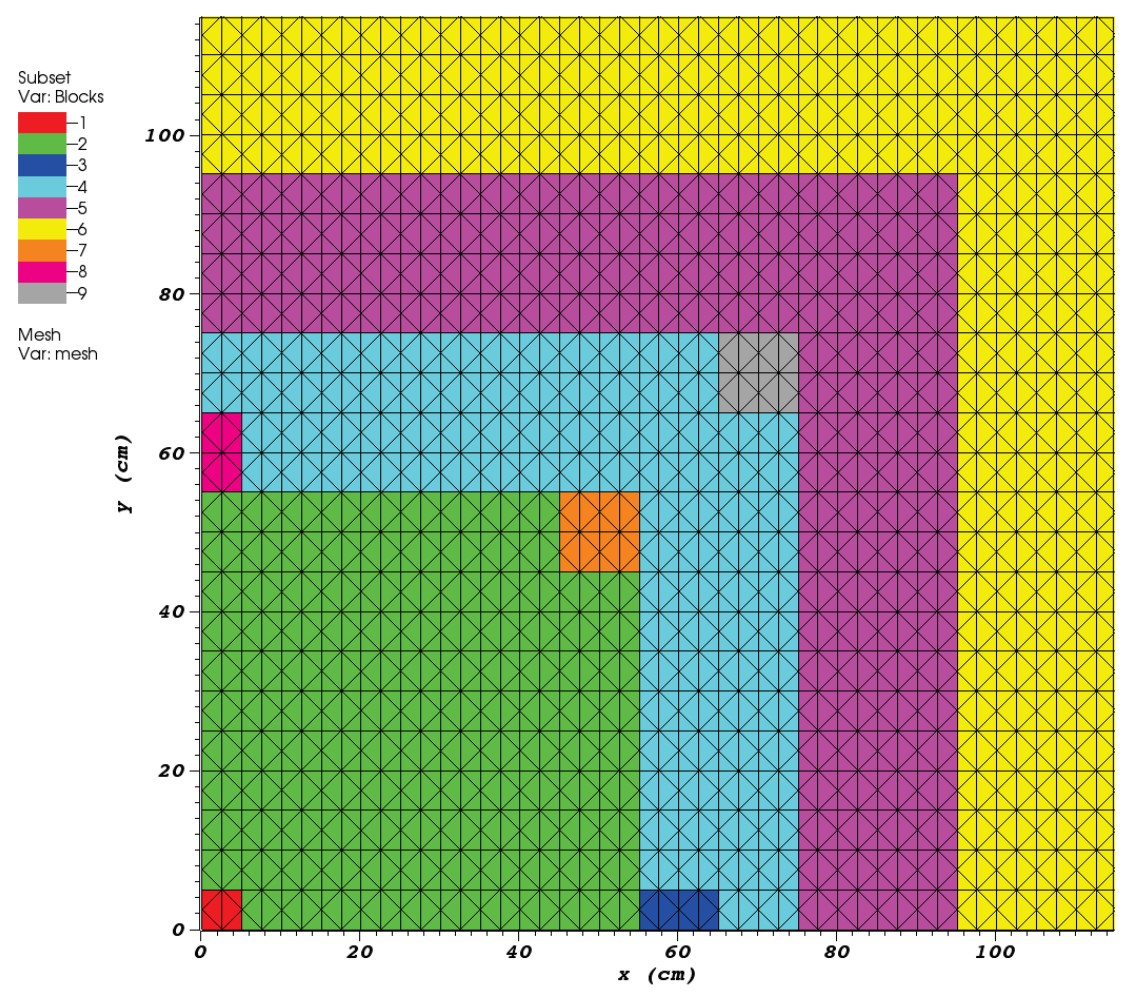

Figure 10. Simplified SFR test problem mesh and materials.

The nine materials in the problem are described in Table 2. The center rods and the rods on the $x$ - and $y$-axes are inserted. The system is operated for 1157 days, in ten time steps of 115.7 days (1e7 seconds). The two fuel regions are homogenized with the coolant.

\subsubsection{Results}

The eigenvalue is shown in Figure 11, and scalar flux is shown in Figure 12 for each material. The power distribution as a function of time is shown in Figure 13. The absorption rate as a function of time is shown in Figure 14. The flux distributions are shown in Figure 15.

\footnotetext{
${ }^{1}$ The ANLXS library is a simple text format with the same information as the ISOTXS binary, converted to ISOTXS internally by PROTEUS-SN.
} 
Table 2. Problem materials

\begin{tabular}{|c|c|c|c|c|}
\hline Name & Description & Composition & Location & $\begin{array}{c}\text { Color } \\
\text { (see Figure 10) }\end{array}$ \\
\hline R_REFL & Radial reflector & $\mathrm{Na}, \mathrm{Fe}$ & Outermost & Yellow \\
\hline R_BLAN & Radial blanket & $\mathrm{U}-238, \mathrm{O}-16, \mathrm{Na}, \mathrm{Fe}$ & Next outermost & Magenta \\
\hline R_CORE1 & Inner fuel region & $\begin{array}{l}\text { U-238, Pu-239, Na, Fe, O- } \\
16\end{array}$ & Innermost & Green \\
\hline R_CORE2 & Outer fuel region & $\begin{array}{l}\mathrm{U}-238, \mathrm{Pu}-239, \mathrm{Na}, \mathrm{Fe}, \mathrm{O}- \\
16\end{array}$ & Next innermost & Cyan \\
\hline R_ROD1 & Inserted control rod & $\mathrm{Na}, \mathrm{Fe}, \mathrm{O}-16, \mathrm{~B}-10, \mathrm{C}$ & Origin & Red \\
\hline R_ROD2 & Inserted control rod & $\mathrm{Na}, \mathrm{Fe}, \mathrm{O}-16, \mathrm{~B}-10, \mathrm{C}$ & $y$-axis & Pink \\
\hline R_ROD3 & Withdrawn control rod & $\mathrm{Na}$ & $\begin{array}{l}\text { Along diagonal } \\
y=x, \text { on edge of } \\
\text { inner fuel region }\end{array}$ & Orange \\
\hline R_ROD4 & Withdrawn control rod & $\mathrm{Na}$ & $\begin{array}{l}\text { Along diagonal } \\
y=x, \text { on edge of } \\
\text { outer fuel region }\end{array}$ & Grey \\
\hline R_ROD5 & Inserted control rod & $\mathrm{Na}, \mathrm{Fe}, \mathrm{O}-16, \mathrm{~B}-10, \mathrm{C}$ & $x$-axis & Blue \\
\hline
\end{tabular}

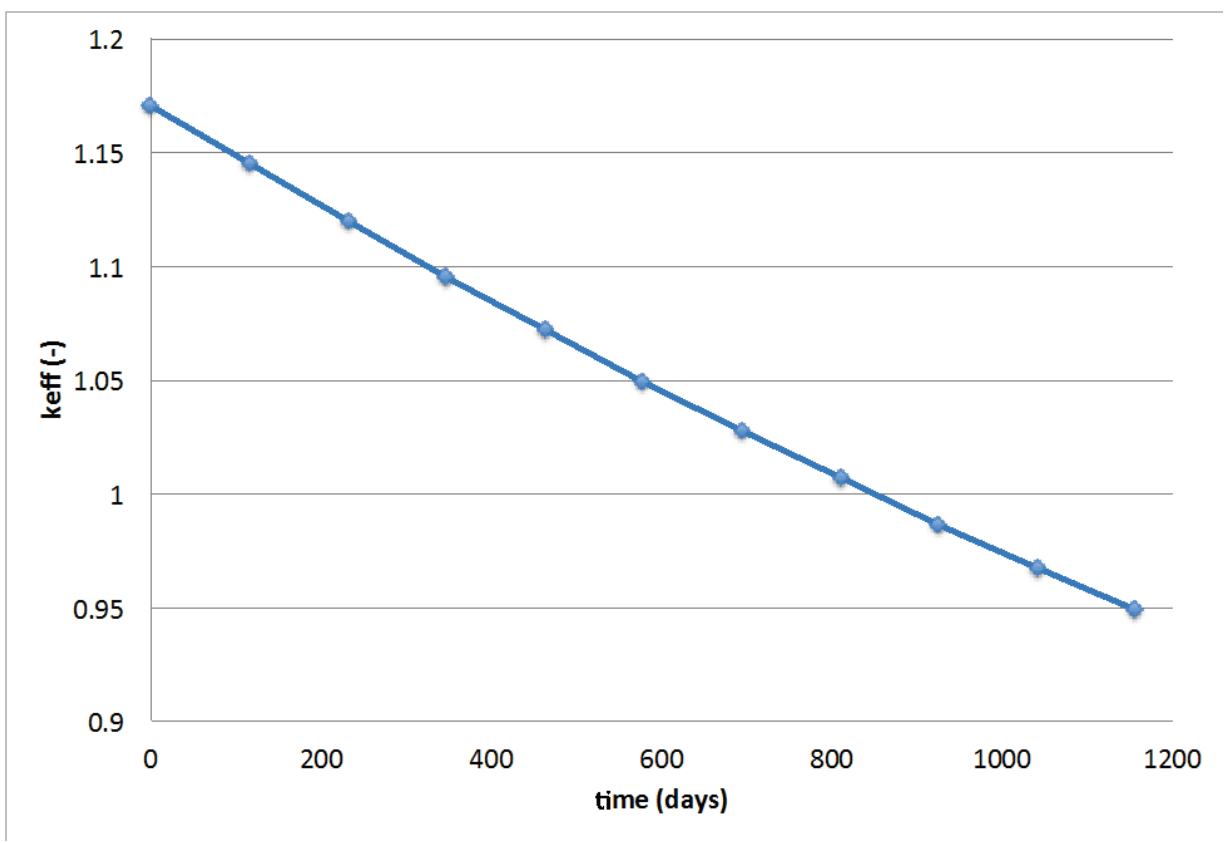

Figure 11. Eigenvalue for simple SFR problem. 


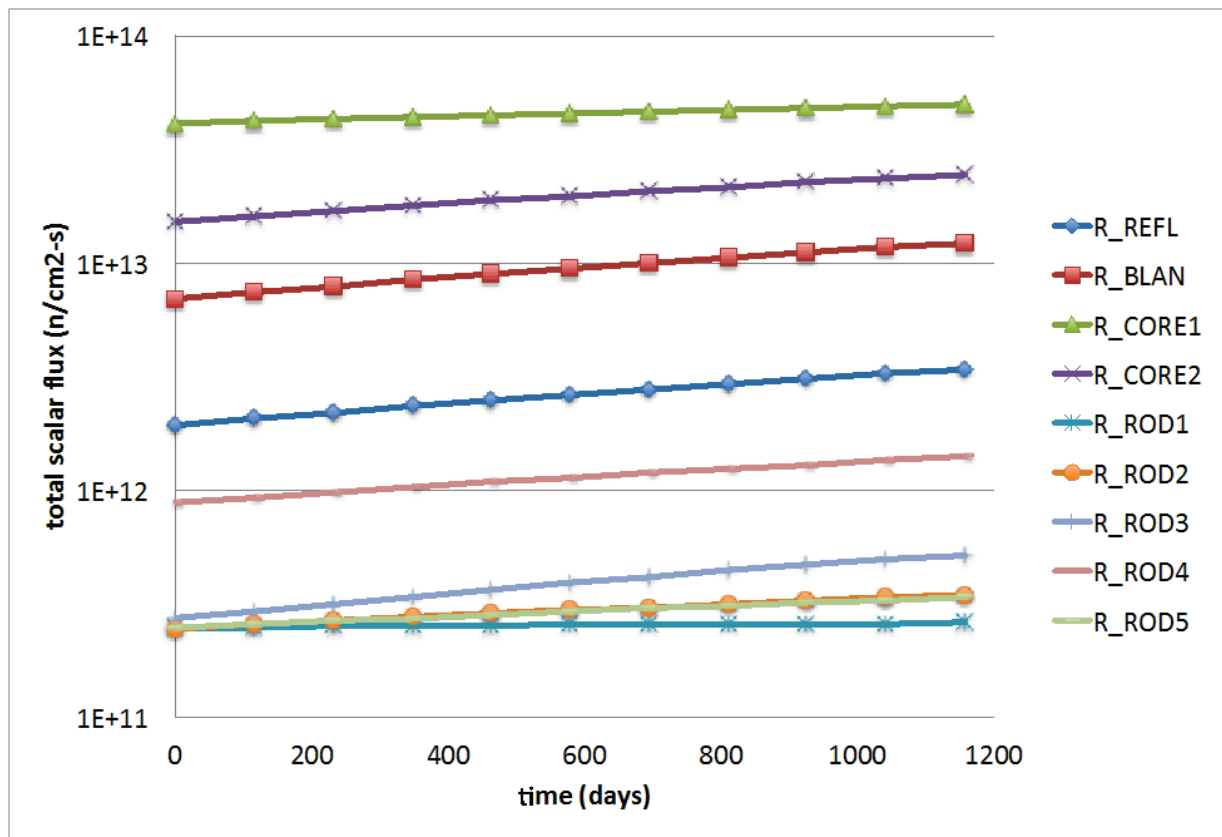

Figure 12. Total scalar flux in each material for simple SFR problem. 


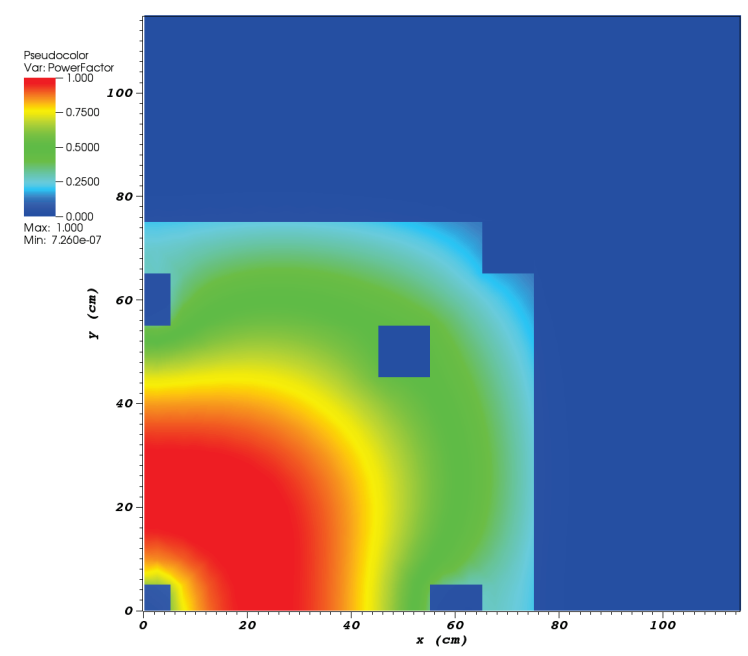

(a) 0 days

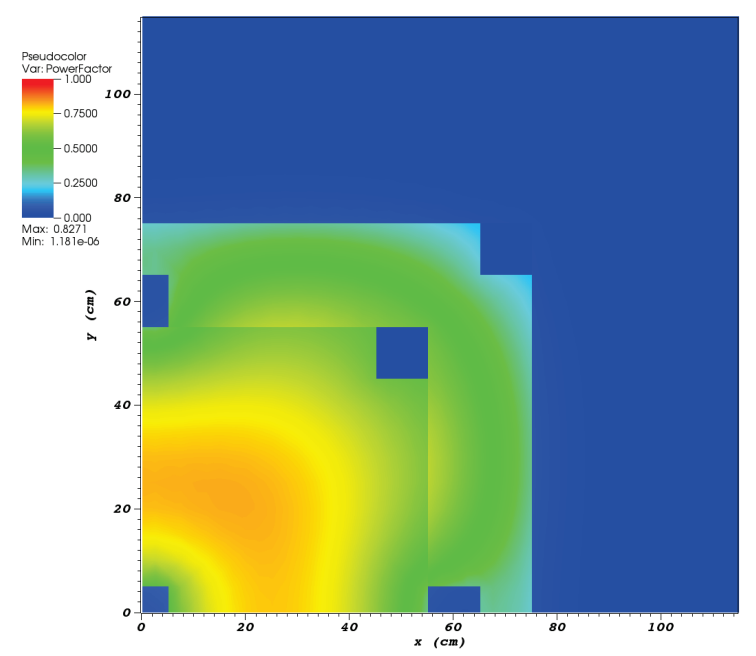

(c) 810 days

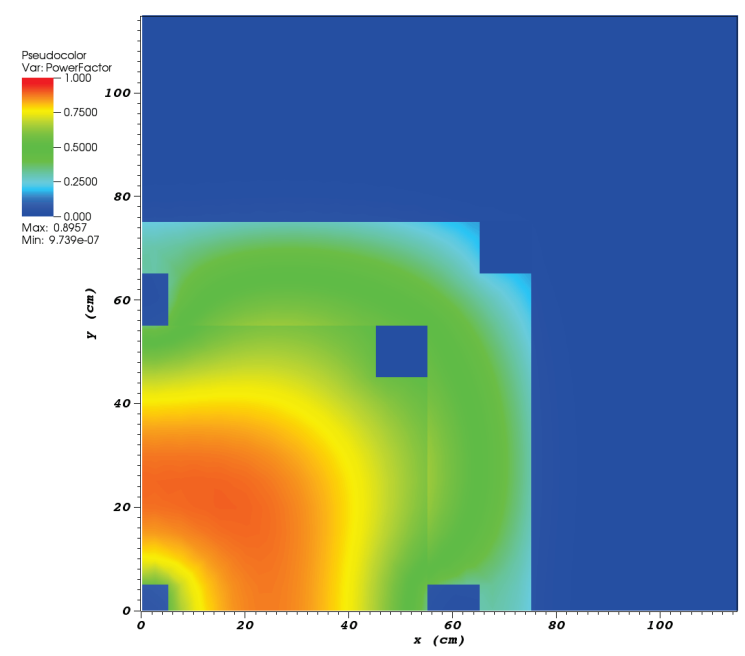

(b) 463 days

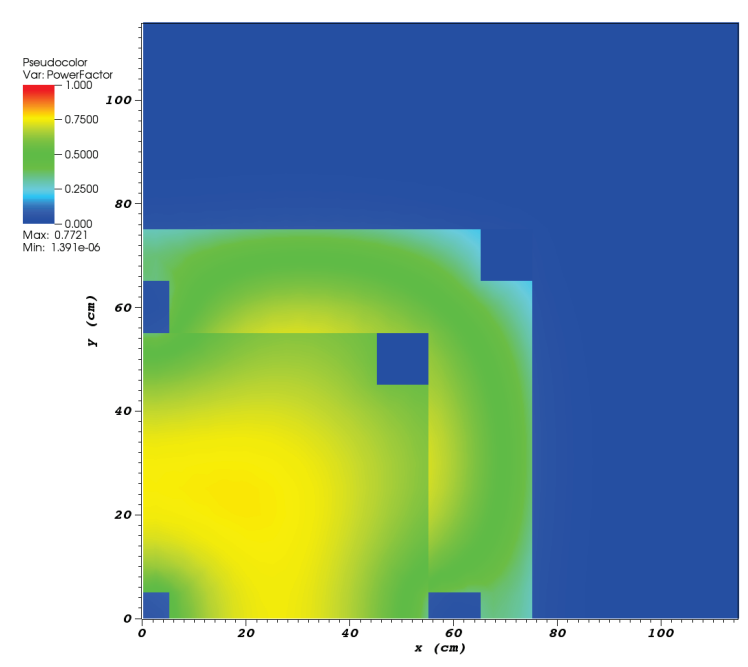

(d) 1157 days

Figure 13. Power distribution in SFR core at various times. 


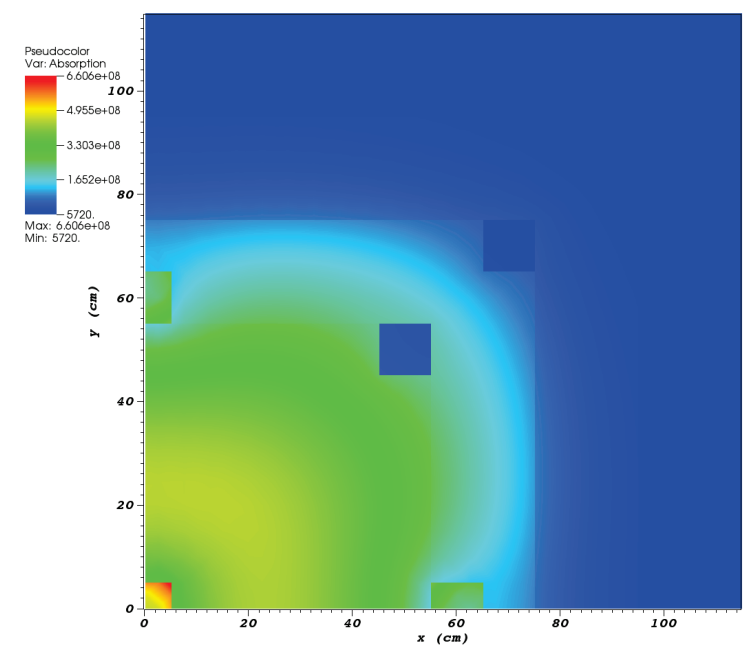

(a) 0 days

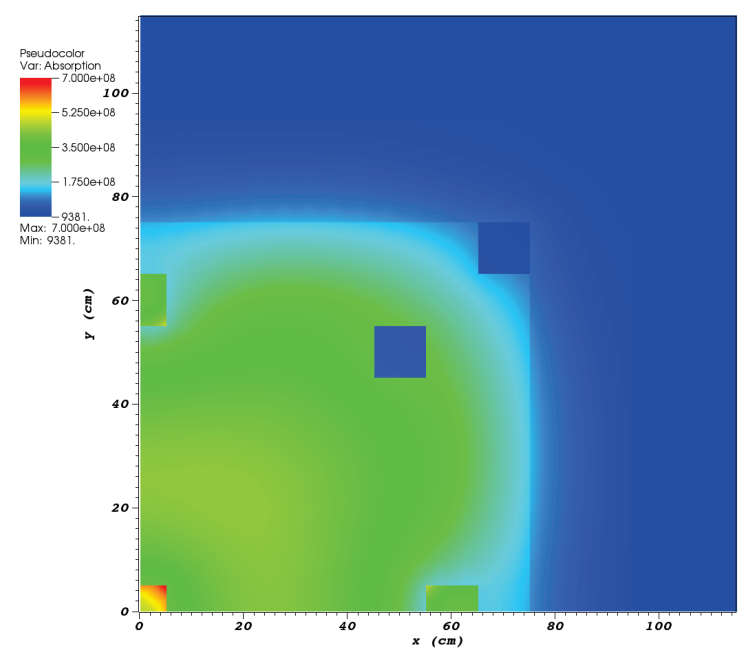

(c) 810 days

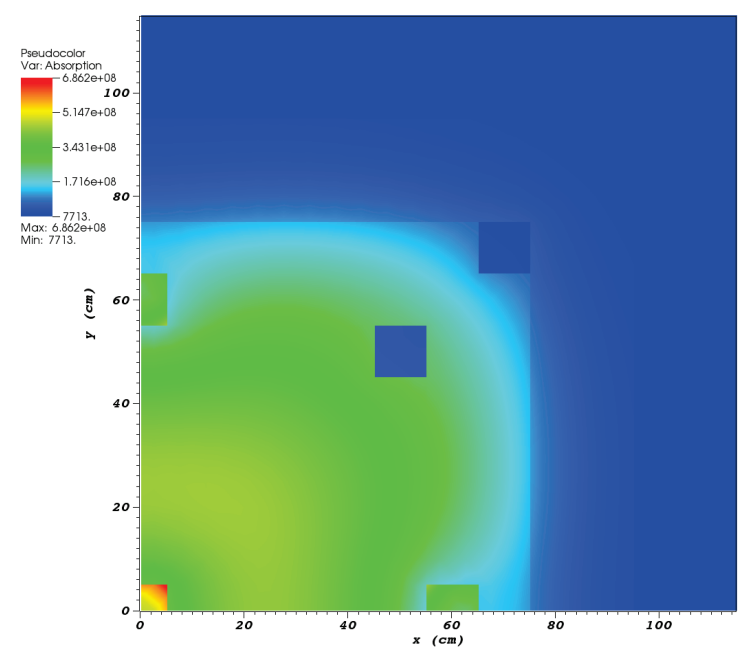

(b) 463 days

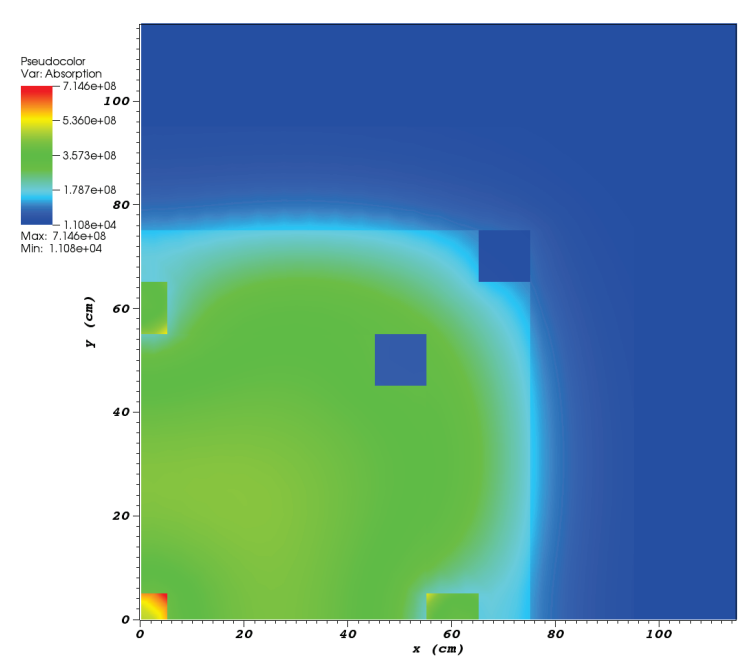

(d) 1157 days

Figure 14. Absorption rate distribution in SFR core at various times. 


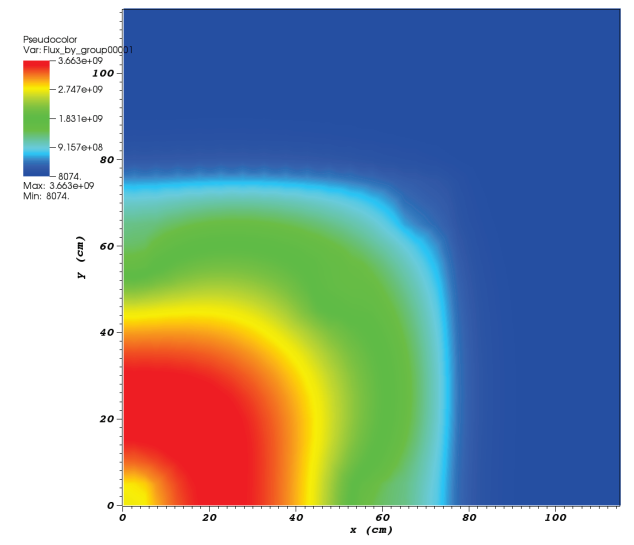

(a) fast flux at 0 days

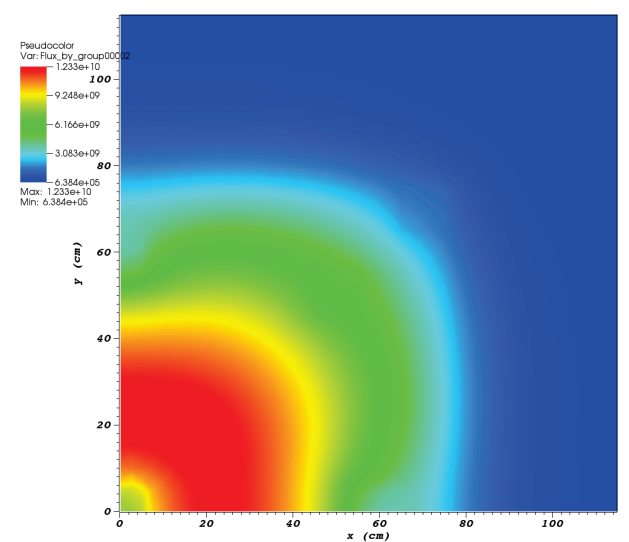

(c) intermediate flux at 0 days

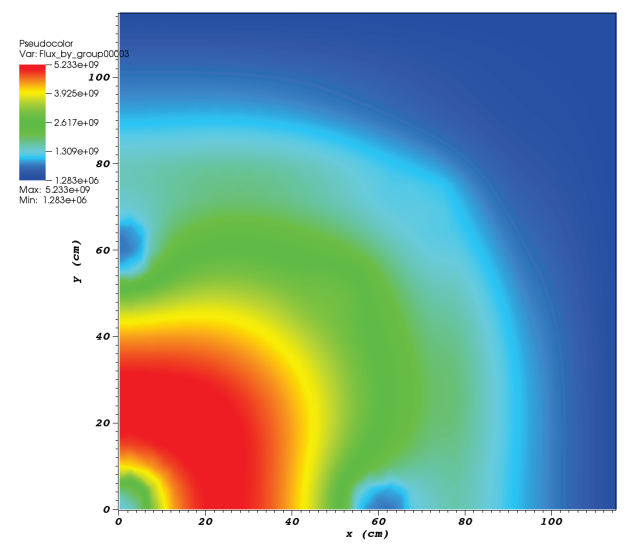

(e) thermal flux at 0 days

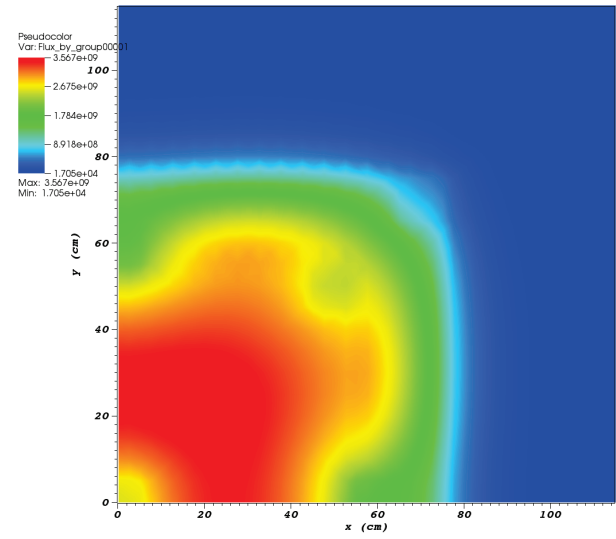

(b) fast flux at 1157 days

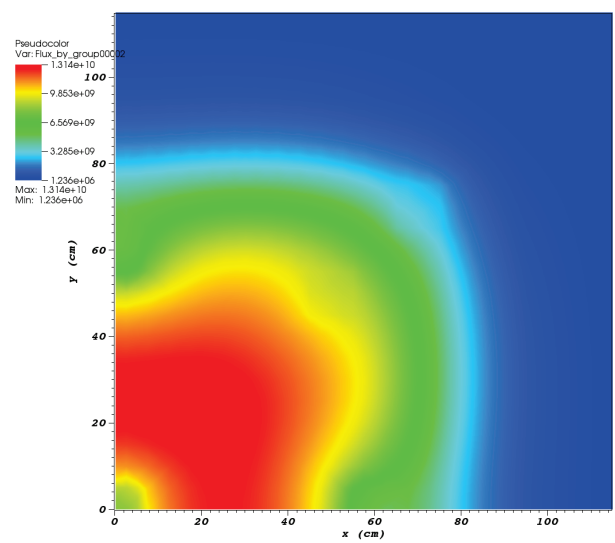

(d) intermediate flux at 1157 days

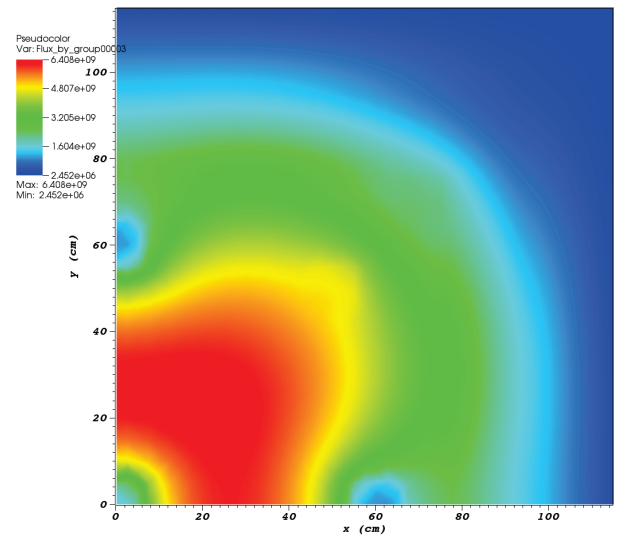

(f) thermal flux at 1157 days

Figure 15. Fast flux, intermediate, and thermal distribution in SFR core at various times. 


\subsubsection{Analysis}

Qualitatively, results for the initial implementation of depletion inside PROTEUS-SN appear reasonable. The eigenvalue shown in Figure 11 decreases as Pu-239 is consumed more than it is generated by U-238. The lack of fission products in the test library leads to no initial sharp drop as fission products burn in and equilibrate. The total scalar flux in Figure 12 for each material shows they are all increasing with time. This is expected due to the fixed power, consumption of fissile material, and hardening of the spectrum. The power distribution in Figure 13 shows flattening with time, and the outer core region power ("R_CORE2") begins to show a discontinuity due to isotopic differences. The absorption rate as a function of time is shown in Figure 14 and shows the effect of the control rods where they are inserted at the origin and on the $x$-axis and $y$-axis. The other two rod locations are pure sodium and do not exhibit the absorption rate of the uranium/plutonium/sodium homogenized fuel mixture. The flux distributions shown in Figure 15 exhibit the spectrum hardening, with the fast and intermediate flux extending to the core periphery. The magnitudes are increasing as well to compensate for loss of fissile material. 


\section{CONCLUSION}

This report has documented the implementation of an initial depletion capability in the PROTEUS-SN code via the ORIGEN API depletion package. The results for a simple SFR test problem look qualitatively reasonable. Future work will address three main avenues of improvement: PROTEUS crosssection library integration, transport/depletion coupling enhancement, and liquid fuel modeling enhancement.

ORIGEN tracks $\sim 1200$ nuclides explicitly, many of them short-lived fission products with no appreciable cross section. However, $\sim 300$ nuclides have evaluated cross sections, and it is important that they all be included in a general-purpose library for PROTEUS. Otherwise, the proper feedback on the neutron transport properties of the system (i.e., macroscopic cross sections) due to isotopes introduced solely from depletion is neglected. In some systems, such as fast reactors, using a small problem-specific library may be easy to justify. However, if PROTEUS-SN is to be a general nuclear system code, a general library must exist and must be included with the distribution. Another issue with the libraries currently in ISOTXS format is that nuclides have arbitrary labels (e.g., "U5H" or "FP"), which are used in case there are two variants of a nuclide that have undergone different self-shielding or flux-weighting processes. Currently, the user is required to input the mapping of the nuclides to an actual nuclide in ORIGEN. A solution is to have in addition to the arbitrary label, an optional standard nuclide identifier, such as the seven-digit IZZZAAA, where I is the isomeric state, ZZZ is three digits of atomic number, and AAA is three digits of atomic mass (e.g., U-235 is 0092235, Am-242m is 1095242, and elemental carbon is 0006000. If the standard nuclide identifier was found, it would enable ORIGEN to directly map a physical nuclide to each ISOTXS library nuclide, and the user would not be required to put this mapping in the input file.

Transport/depletion coupling should be enhanced in future work by implementing a predictor/corrector methodology, whereby much more accurate solutions in time can be obtained. Additionally, the ability to specify time-dependent power levels and to produce HDF5 outputs of the isotopic distributions must be implemented.

Separate depletion zones introduce nonphysical isotopic distributions in a fuel that is constantly mixing. Therefore, more development is needed before liquid fuel systems such as molten salt reactors can be modeled. Specifically, additional development is needed so that fuel zones designed to allow variations in density, temperature, and cross section do not create separate depletion zones. Liquid fuel also experiences intermittent decay and fission product removal while in the out-of-core part of the loop. If this is a desirable system to model with PROTEUS-SN, then an appropriate liquid fuel model must be developed. 


\section{REFERENCES}

1. W. A. Wieselquist, ORIGEN FY 2014 End-of-Year Status Report for NEAMS Including Prototype API User's Guide, ORNL/LTR-2014/544, Oak Ridge National Laboratory, Oak Ridge, Tennessee, September 31, 2014.

2. E. R. Shemon, M. A. Smith, and C. H. Lee, PROTEUS-SN Methodology Manual, ANL/NE-14/5, Argonne National Laboratory, Argonne, Illinois, June 30, 2014.

3. E. R. Shemon, M. A. Smith, C. H. Lee, and A. Marin-Lafleche, PROTEUS-SN User Manual (Revision 1.0), ANL/NE-14/6, Argonne National Laboratory, Argonne, Illinois, August 4, 2014.

4. H. Childs, et al. "VisIt: An End-User Tool For Visualizing and Analyzing Very Large Data," pp. 357-372 in High Performance Visualization-Enabling Extreme-Scale Scientific Insight, CRC Press, Taylor and Francis Group, Boca Raton, Florida, 2012.

5. I. C. Gauld, G. Radulescu, G. Ilas, B. D. Murphy, M. L. Williams, and D. Wiarda, "Isotopic Depletion and Decay Methods and Analysis Capabilities in SCALE," Nuclear Technology 174(2), 169 (2011).

6. G. Ilas, I. C. Gauld, and H. Liljenfeldt, "Validation of ORIGEN for LWR used fuel decay heat analysis with SCALE," Nuclear Engineering and Design, 273, 58-67 (2014).

7. G. Ilas, I. C. Gauld, and G. Radulescu, "Validation of New Depletion Capabilities and ENDF/B-VII Data Libraries in SCALE," Annals of Nuclear Energy 46, 43-55 (2012).

8. B. T. Rearden and M. A. Jessee, Eds., SCALE Code System, Version 6.2, ORNL/TM2005/39, Oak Ridge National Laboratory, Oak Ridge, Tennessee, 2016. Available from Radiation Safety Information Computational Center as CCC-834.

9. B. Kochunas, B. Collins, D. Jabaay, K.S. Kim, A. Graham, S. Stimpson, W. Wieselquist, K. Clarno, A. Godfrey, S. Palmtag, T. Downar, and J. Gehin, "MPACT Methodology for PWR Cycle Depletion," Proc. M\&C \& SNA 2014, Nashville, Tennessee, USA. April 19-23 (2015) 